\title{
Combustion of coal water slurry-technology enabling the achievement of a reduced technical minimum of the boiler
}

\author{
Krzysztof Głód ${ }^{1, *}$, Janusz Lasek ${ }^{1}$, Krzysztof Słowik ${ }^{1}$, Jarosław Zuwała ${ }^{1}$ \\ ${ }^{1}$ Institute for Chemical Processing of Coal, ul. Zamkowa 1, 41-803, Zabrze, Poland
}

\begin{abstract}
The idea of combustion of suspended fuels was developed in the 1980s. The largest producer and user of slurry fuels (Coal Water Slurry, CWS) is China [3]. Despite of several decades of CWS research history, investigations are still carried out to improve the parameters of disperse fuels and to improve the combustion of these fuels. The close relationship between the properties of slurry fuels and number of parameters (mainly the type and properties of the coal feedstock) generates the necessity of CWS receipts and determines for what purposes the fuel may be destined. In the case of the use of coal sludge, the resulting slurry allows for the combustion / "disposal" of coal slurry in pulverized boilers. In the case of using better quality fine coal fractions in CWS production, a slurry will be created allowing for achieving the crucial technological goal such as operation of power units with a reduced technical minimum.
\end{abstract}

\section{Introduction}

The idea of burning slurry fuels, also known as coal-water suspension or Coal Water Slurry (CWS), was intensively developed in the 1980s. The combustion of slurry fuel may be carried out in fluidised bed boiler [1], as well as by employing a burner in which fuel is sprayed behind the nozzle [2]. China is recognized as the largest producer and user of slurry fuels (carbon-water suspensions) [3]. Despite of several dozen years of history, a lot of research is still being carried out to improve the quality parameters of slurry fuels, as well as to the improve its combustion process. There is a strict correlation between the quality of slurry fuel and number of parameters, including in particular the type and properties of "feedstock coal". They determine the formulas and technical procedures for production of CWS from available "at the moment" coal resources. Therefore, the research on slurry fuels is focused on adjusting the formulas and procedures of their preparation to specific coals, determining the properties of the fuel (i.e. rheological properties, viscosity, stability) and observing its behavior during hydraulic transport and in the final utilization process (e.g. combustion or/and gasification) [4-11]. It was observed that the ignition of slurry fuel can be achieved in the temperature range of $420-480^{\circ} \mathrm{C}$, although it is then necessary to grind the coal particles to the size range of $1-10 \mu \mathrm{m}$ [9]. From the engineering point of view the results presented in the paper Walsh and co-workers [12] presented very important results

\footnotetext{
*Corresponding author: kglod@ichpw.pl
} 
in terms of engineering practice of CWS combustion in scale of $1 \mathrm{MW}$ burner.. These researchers noted that the ignition temperature was $860 \mathrm{~K}$ and the evaporation, ignition and combustion time of individual fractions strongly depend on the diameter of the fuel particles and the diameter of slurry. For the fuel particles diameter over $50 \mu \mathrm{m}$, total and complete combustion took place at a distance of $4 \mathrm{~m}$ from the burner (which corresponded to a flue gas residence time of more than $16 \mathrm{~ms}$ at the assumed flow rate). The use of suspended particles below $20 \mu \mathrm{m}$ shortened the "combustion path" to about $2 \mathrm{~m}$.

The use of slurry fuel allows for sustainable development of the energy company by managing of small coal fractions derived from coal processing while increasing the efficiency of electricity generation.

Stable and cost-efficient operation of power units in the lower load range is a significant challenge for Polish enterprises. This issue is particularly important in summer and transient periods (mid-spring to mid-autumn). Then, boilers load are changed frequently and the boilers are operated with an acceptable minimum or even the boilers shutdown is considered. Such situation cause the increase of operational costs due to necessity of liquid fuels application and the operation of boiler outside the rated parameters. The use of slurry fuel produced from fine coal fractions is expected to bring economic benefits due to the following issues:

- for the replacement of liquid fuels (light oil, heavy fuel oil) by cheaper slurry fuel,

- stabilization of the combustion process in the chamber through the installation of additional independent burners enabling the reduction of the working mills number, , the enhancement of by primary methods of NOx removal,

- maintaining nominal temperatures of steam at the boiler outlet (especially secondary steam) due to the properties of the flue gas containing higher concentration of water vapor.

\section{Operating conditions of the boiler with the technical minimum}

In order to assess the possibility of using slurry fuel during operation of the boiler and its equipment at minimum load, it is necessary to analyse the operating conditions and parameters which are obtained at such load.

The technical minimum of the boiler is the lowest load, during stable operation is possible without assistance additional fuel burning and when the emission parameters are consistent with the standards. In the case of the most common power units using pulverized fuel, PF combustion technology, the most important conditions determining the possibility of working with low loads are: circulation in the evaporator, compliance with the parameters of steam fed to the turbine, operation of mill units affecting the combustion stability in the furnace chamber and NOx emissions.

In the majority of cases of power boilers operated for several dozen years (designed on the assumption of their operation under load close to the rated parameters), the above mentioned conditions can be met by carrying out a deep modernization of the existing boiler equipment and the boiler itself, adjusting it to the scope of operation under low loads.

An alternative solution is to use the technology of burning slurry fuel, the cost of which is lower than the used petroleum fuels. The results of the cost analysis of slurry fuel production, depending on the price of coal from which it was made, are presented in Fig. 1. During the analysis, it was assumed that the combustion of suspended fuel takes place through the use of an independent fuel feeding installation with its associated burners. 


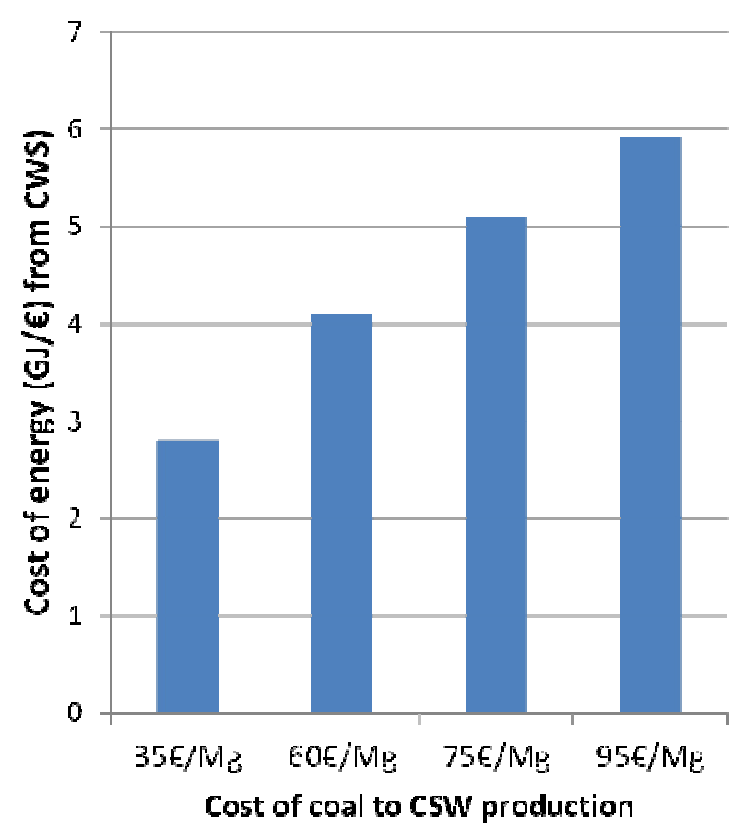

Fig. 1. Costs of slurry fuel.

From the thermodynamic point of view, the use of carbon-water slurry, i. e. a fuel with a very high moisture content of up to $60 \%$, reduces the calorific value by losing the energy necessary to evaporate the water. The so-called hidden enthalpy of evaporation is rarely recovered in currently operated boilers, because the heat collection systems used are not adapted to the condensation of steam in an aggressive flue gas environment.

The use of a system for the recovery of "evaporation enthalpy" can, in certain cases, bring energy (technological) as well as financial benefits.

The technology of combustion of suspended fuels allows for the management of small coal fractions, including sludge and fleets. If a low-energy feedstock is used in the production of suspended solids, this technology will only allow for the "utilization" of such fuel, reducing the costs associated with other management of this material, (mainly its disposal). In this case, significant support with primary fuel is needed to allow stable and complete combustion of suspended fuel because its low heating value, LHV of the CWS drops to $4500 \mathrm{~kJ} / \mathrm{kg}$.

Using a fine coal fraction with good energy properties (when LHV of obtained CWS is higher than $10000 \mathrm{~kJ} / \mathrm{kg}$ ), the prepared slurry allows to achieve another objective, which may be to reduce the technical minimum of the boiler. In this case, the effects obtained significantly outweigh the disadvantages of using slurry fuel (Fig. 2). 


\section{The use of petroleum fuel}

\begin{tabular}{|l|}
\hline BENEFITS: \\
\hline Bonuses for availability \\
$\square$ Lower start-up costs \\
$\square$ Lower repairing costs \\
\hline
\end{tabular}

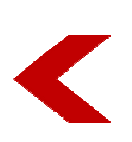
DISADVATAGES:

Higher fuel costs $(\sim 8,2 € / G J$ HFO $)$

$\square$ Lower production efficiency

\section{The use of slurry fuel}

BENEFITS:
a Bonuses for availability
$\square$ Lower start-up costs
Lower repairing cost
lower energy consumption of technologies
$\square$ Low fuel costs $(\sim 4.2 € / G J$ CWS $)$

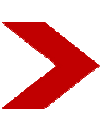

DISADVATAGES:

$\square$ Lower production efficiency

Fig. 2. Benefits and disadvantages of working at a reduced minimum.

In recent years, there have been more frequent periods when power plants operate at low loads, and even it is necessary to put them to a warm state in order to restart them in a few or several hours. This situation significantly affects the technical condition of the equipment and the service life of thick-walled elements of the boiler and turbine, which ultimately affects the operating costs of the production unit.

\section{The analysis of the impact of the slurry fuel application on a boiler operation with low load}

The low boiler load affects the change in the nature of heat exchange, and thus the thermal loads of heating surfaces.

In such case, heat transfer in radiation zone of the boiler is increased (due to higher concentration of water vapor in flue gas) and heat transfer in convection zone is decreased.

Replacement of a part of the primary fuel by CWS affects the heating surfaces in two ways:

- decrease of combustion temperature in the furnace chamber, stabilizing the combustion process with additional independent burners, affecting the temperature decrease of the metal elements of superheaters,

- increase of exhaust gas stream, comparing to combustion of the main fuel. In the case of replacing the $15 \%$ share of energy with the primary fuel, the flue gas stream is increased by almost $25 \%$, which allows to increase the efficiency of heat exchange on convection surfaces and thus maintain the parameters of secondary steam at the required level.

During operation at low boiler load for maintaining safety and stable combustion process in the combustion chamber, depending on the size of the boiler, it is necessary to use at least two or three mill sets. These systems most often work at the edge of the range with suboptimal parameters. This is due to the need to work with enhanced ventilation to maintain a minimum flow through the mill and to maintain adequate air velocity in the dust-pipes and the burner, and to maintain the temperature of the dust-air mixture by increasing the amount of cold air added.

The possibility of replacing a part of the primary fuel by slurry fuel (cheaper than the petroleum fuel and operated using independent burners), improves the flame stability in the 
furnace chamber. Additionally, it allows to decrease the number of working mills and increase the load of other units (boilers) in the optimal work area (Fig. 3).
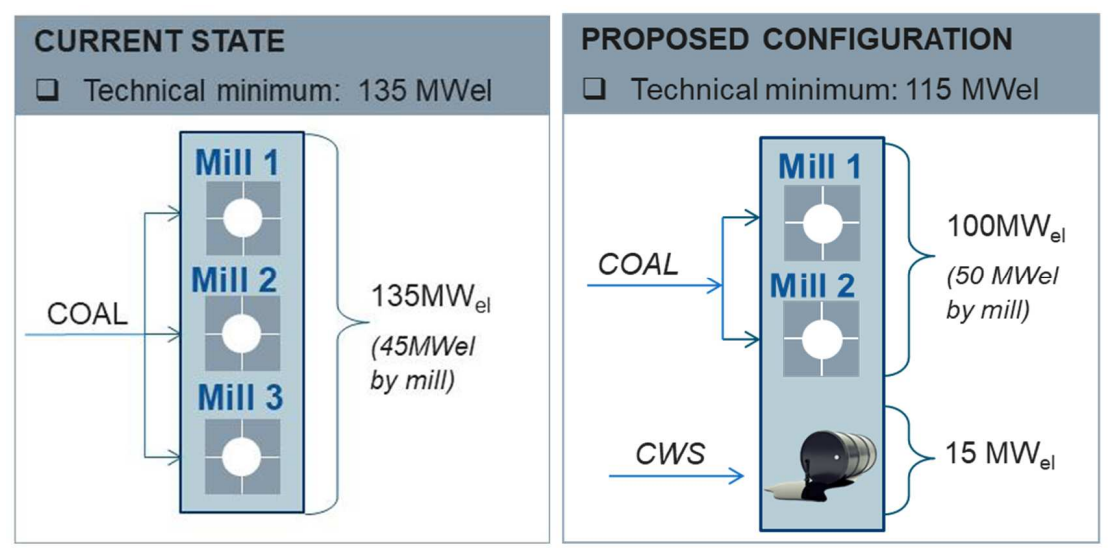

Fig. 3. Configuration of operation of mill sets at low load

The work of the mills system in the optimum range of parameters plays a major role in the control of NOx emissions at an acceptable level. During the combustion of the slurry fuel, water existence decreases the flame temperature in the combustion chamber and it reduces the possibility of the NOx formation. The possibility of obtaining low NOx emissions was confirmed by the Institute's own research (Figure 4) and by research conducted in other centers [13].

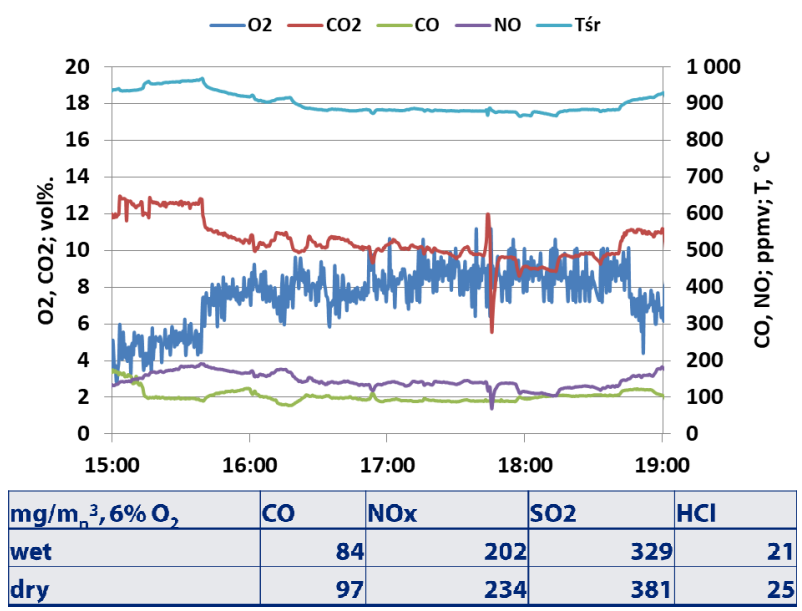

Fig. 4. The emissions of selected pollutants during combustion of slurry fuel.

The possibility of arranging independent burners at selected levels causes more uniform temperature field in the furnace chamber and improve the operation of additional NOx emission reduction systems.

\section{Summary}


The use of slurry fuel, coal water slurry (CWS), i.e. a mixture of fine coal, water and additives seems to be a seemingly irrational solution, contrary to engineering practice due to the "thermodynamic aspects" (mainly the need to evaporate the water introduced with the fuel into the combustion chamber). However, if this technology is used for the specific purpose of combustion of the fine fraction generated in the coal processing process, a number of measurable benefits can be demonstrated in the overall balance sheet settlement (fine coal management, fuel production, boiler combustion, balancing, taking into account operating states at low load as well as the potential need to stop the boiler). It should be noted that stable and energy-efficient combustion of slurry fuels is possible. It was confirmed experimentally using technical-scale $\left(200 \mathrm{~kW}_{\text {th }}\right)$ unit.

From the research conducted by the Institute for Chemical Processing of Coal and other scientific groups, it has been proved that the use of disperse fuels allows to obtaina reduced boiler minimum and lower emissions of major gaseous pollutants, without significant interference in the existing boiler infrastructure. It avoids significant investment cost to adopt CWS combustion in existing boilers.

\section{Acknowledgements}

These investigations were carried out in Clean Coal Technology Center situated in Institute for Chemical Processing of Coal. The results presented in this paper were obtained during the research projects entitled "The development and improvement of the technology combustion of coal-water slurry" (IChPW No. 11.18.004) and "The investigations of coalwater slurry combustion realized in a dedicated burner" (IChPW No. 11.17.019), financed by the Ministry of Science and Higher Education, Poland.

\section{References}

1. X. Zhao, W. Zhu, J. Huang, M. Li, M. Gong Emission characteristics of PCDD/Fs, PAHs and PCBs during the combustion of sludge-coal water slurry. Journal of the Energy Institute. 2015;88(2):105-11.

2. L. Jianzhong, W. Ruikun, X. Jianfei, Z. Junhu, C. Kefa Pilot-scale investigation on slurrying, combustion, and slagging characteristics of coal slurry fuel prepared using industrial wasteliquid. Applied Energy. 2014;115:309-19.

3. A. Michalik, J. Hycnar, H. Kula, A. Fraś, L. Sikora Zakres i warunki stosowania suspensji węglowo-wodnych. Conference Zakres i warunki stosowania suspensji węglowo-wodnych, Zakopane. p. 75.

4. TX. Phuoc, P. Wang, D. McIntyre, L. Shadle Synthesis and characterization of a thixotropic coal-water slurry for use as a liquid fuel. Fuel Processing Technology. 2014;127:105-10.

5. F Yi, A Gopan, RL. Axelbaum Characterization of coal water slurry prepared for PRB coal. Journal of Fuel Chemistry and Technology. 2014;42(10):1167-71.

6. P Phulkerd, N Thongchul, K Bunyakiat, A. Petsom Coal water slurry using dispersant synthesized from cashew nut shell liquid (CNSL). Fuel Processing Technology. 2014;119:256-62.

7. G. Zhang, J. Li, J. Zhu, Q. Qu, W. Xiong. Syntheses and evaluations of three sulfonated polycondensate dispersants for coal-water slurries. Powder Technology. 2014;254:572-8. 
8. J. Zhu, G. Zhang, G. Liu, Q. Qu, Y Li. Investigation on the rheological and stability characteristics of coal-water slurry with long side-chain polycarboxylate dispersant. Fuel Processing Technology. 2014;118:187-91.

9. J. Cheng, J. Zhou, Y. Li, J. Liu, K. Cen. Effects of pore fractal structures of ultrafine coal water slurries on rheological behaviors and combustion dynamics. Fuel. 2008;87(12):2620-7.

10. L. Chen, Y. Duan, M. Liu, C Zhao Slip flow of coal water slurries in pipelines. Fuel. 2010;89(5):1119-26.

11. Z. Yun, G. Wu, X. Meng, Y. Zhang, F. Shi, Y. He, et al. A comparative investigation of the properties of coal-water slurries prepared from Australia and Shenhua coals. Mining Science and Technology (China). 2011;21(3):343-7.

12. PM. Walsh, M. Zhang, WF. Farmayan, JM. Beér Ignition and combustion of coalwater slurry in a confined turbulent diffusion flame. Symposium (International) on Combustion. 1985;20(1):1401-7.

13. M. Dmitrienko, G. Nyashina, P. Strizhak Major gas emissions from combustion of slurry fuels based on coal, coal waste, and coal derivatives Journal of Cleaner Production 177 (2018) 284-301 